\title{
PENGENALAN GREEN BEHAVIOUR MELALUI ECOLITERACY PADA ANAK USIA DINI
}

\author{
Suci Utami Putri (suciutami@upi.edu) ${ }^{1}$ \\ Gia Nikawanti (gianikawanti87@gmail.com)²
}

\begin{abstract}
ABSTRAK
Studi ini bertujuan untuk memberikan deskprisi mengenai ecoliteracy sebagai salah satu upaya untuk membangun green behaviour pada anak usia dini. Pada abad 21 pardigma isu yang berkembang berhubungan dengan isu-isu global salah satunya adalah isu tentang earth issue yang di dalam kajiannya terdapat kajian tentang pentingnya manusia untuk melindungi dan menjaga keseimbangan ekosistem. Pengenalan green behaviour melalui ecoliteracy sangat penting diberikan pada anak melalui peran orang dewasa. Anak harus mempunyai kesadaran dalam mencintai lingkungan sehingga ketika anak sudah mempunyai kesadaran untuk mencintai lingkungan maka anak dengan senang hati akan memperlihatkan perilaku untuk menjaga alam semesta. Pada studi ini, dilakukan kajian literatur terhadap berbagai sumber terkait ecoliteracy yang relevan dengan penanaman sikap green behaviour untuk anak usia dini. Hasil analisis kajian dari berbagai sumber ini kemudian dijadikan dasar dalam merumuskan sebuah strategi pengenalan sikap ramah lingkungan yang relevan untuk anak usia dini .
\end{abstract}

Kata Kunci: Pengenalan green behaviour, ecoliteracy, anak usia dini

\section{A. PENDAHULUAN}

Paradigma isu yang berkembang pada abad 21 berhubungan dengan isu global salah satunya adalah isu yang berhubungan dengan lingkungan hidup. Lingkungan hidup dianggap sebagai suatu akses manusia untuk mencapai suatu kesejahteraan. Lingkungan hidup bukan hanya dianggap sebagai tempat makhluk hidup untuk tinggal di dalam suatu tempat saja, namun lebih dari itu lingkungan hidup adalah suatu produktivitas kesinergisan alam semesta yang di dalamnya terjalin kontak kehidupan antara alam dan perilaku makhluk hidup.

Wujud perilaku makhluk hidup dalam menjaga alam semesta tersebut disebut sebagai green behaviour. Golman \& Barlow (2012) menjelaskan bahwa green behaviour adalah perilaku manusia dalam menjaga dan memelihara lingkungan hidup yang berada di lingkungan terdekatnya. Green behaviour muncul dikarenakan adanya kesadaran manusia untuk mencintai alam semesta. Kesadaran seseorang untuk mencintai alam semesta tersebut harus ditanamkan sedari dini pada anak salah satunya melalui ecoliteracy.

Ecoliteracy adalah kesadaran manusia dalam menjaga dan melestarikan alam. Kesadaran tersebut dapat dimiliki oleh individu melalui proses pembelajaran sepanjang hayat yang pada akhirnya akan membentuk pengetahuan, sikap, watak, dan keterampilan dalam mengolah serta melestarikan alam. Hal ini sejalan dengan penjelasan dari Capra (2010) bahwa ecoliteracy adalah kesadaran moral komunitas manusia untuk menghargai komunitas biotik. Kedudukan manusia dalam ecoliteracy ialah melek akan isu-isu kritis serta memberikan solusi efektif dan bijak yang berhubungan dengan lingkungan hidup baik di lingkungan manusia itu tinggal maupun lingkungan hidup secara global.

Maka dari itu cara untuk mengenalkan anak usia dini agar mereka sadar akan pentingnya mencintai alam semesta yaitu dengan cara menanamkan ecoliteracy. Ecoliteracy bagi anak usia dini adalah mengenalkan kesadaran anak untuk memelihara dan menjaga

\footnotetext{
${ }^{1}$ UPI Kampus Purwakarta

${ }^{2}$ STKIP Purwakarta
} 
lingkungan sekitar dengan menggunakan pendekatan yang sesuai dengan tahapan perkembangan kognitif anak sehingga pada akhirnya mereka memiliki perilaku cinta pada lingkungan yang diimplementasikan pada kehidupan mereka sehari-hari. Berlandaskan dari pemaparan latar belakang di atas, melalui artikel ilmiah ini akan dipaparkan mengenai deskripsi teori mengenai ecoliteracy serta green behaviour yang akan mengantarkan pada sebuah rumusan argumentasi mengenai strategi pengenalan green behaviour untuk anak usia dini.

\section{B. KAJIAN TEORI}

\section{Green Behaviour}

Green behaviour adalah perilaku menjaga dan memelihara lingkungan hidup yang dilakukan karena adanya kesadaraan dan rasa tanggung jawab atas kelestarian alam semesta. Seperti yang dijelaskan oleh Keraf (2014) bahwa pada dasarnya manusia mempunyai rasa memiliki dan mencintai alam tempat dirinya hidup sehingga seharusnya manusia mampu belajar berhadapan dengan lingkungannya.

Green behaviour harus mewujud menjadi tindakan yang dilandasi oleh nilai, norma dan kasih sayang terhadap alam semesta. Pola-pola green behaviour dapat dilihat dari perilaku individu sehari-hari seperti memelihara kebersihan lingkungan rumah, membuang sampah pada tempatnya, mengonsumsi makanan sehat, mendaur ulang sampah rumah tangga, menggunakan listrik dan air seperlunya. Sejalan dengan pengertian green behaviour dari Capra (2010) yang menjelaskan bahwa green behaviour manusia dapat dikatakan sebagai etika manusia dalam memperlakukan lingkungan hidupnya. Fokus dari green behaviour yaitu kaidah moral manusia dalam menjiwai perilaku cinta terhadap alam semesta.

Green behaviour merupakan refleksi dari tanggung jawab serta kepedulian terhadap lingkungan yang harus ada dan dimiliki oleh setiap manusia. Pembentukan perilaku manusia terhadap lingkungan berhubungan dengan sikap dan nilai yang bersumber dari pengetahuan, perasaan dan kecenderungan bertindak. Dari hal itu tindakan manusia terhadap lingkungan dilakukan berdasarkan keputusan yang berasal dari informasi lingkungan dan dari latar belakang pengalaman serta sikap terhadap lingkungan.

Hal menarik dari green behaviour dalam hubungan manusia dengan lingkungan sekitarnya adalah identitas tempat dan kesadaran lingkungan. Identitas tempat adalah substruktur dari identitas diri seseorang yang berisikan pengetahuan mengenai lingkungan fisik tempat dia hidup. Hal ini terkait dengan tempat yang berarti dan secara emosi memiliki makna hidup bagi dirinya. Green behaviour diharapkan menjadi sebuah gaya hidup yang dimiliki oleh seluruh individu pada abad 21. Green behaviour sebagai gaya hidup akan menciptakan keseimbangan ekosistem sehingga alam dan makhluk hidup di dalamnya dadpat hidup sejahtera. Tentunya hal tersebut bukanlah seseuatu yang dapat diciptakan tanpa adanya usaha nyata.

Syaodih \& Handayani (2015) di dalam penelitiannya memaparkan bahwa green behaviour perlu ditumbuhkan sedari dini kepada anak-anak agar di masa depan anak-anak akan menjadi makhluk dewasa yang mempunyai perilaku hijau mencintai alam semesta. Bentuk menumbuhkan green behaviour pada anak usia dini adalah dengan memberikan bentuk pembelajaran proyek sehingga dapat menumbuhkan keterampilan berpikir kritis pada anak, menumbuhkan keterampilan menyelesaikan masalah pada anak, dan menjadikan anak sebagai pelajar yang mandiri. Anak-anak diberikan pengetahuan yang disertai dengan praktik tentang pentinya menjaga lingkungan sekitar seperti cara menghemat air, cara memelihara tanaman, serta memilah sampah organik dan non-organik.

Penelitian yang dilakukan oleh Syaodih \& Handayani diperkuat oleh penelitian sebelumnya yang dilakukan oleh Dahlia (2014) yang menyatakan bahwa green behaviour sangat penting diberikan pada anak usia dini melalui pemberian pendidikan wawasan 
lingkungan hidup dan pembentukan budi pekerti agar anak dapat memiliki nilai-nilai cinta terhadap lingkungan yang diwujudkan dalam perilakunya sehari-hari.

\section{Ecoliteracy}

Ecoliteracy adalah istilah yang pertama kali digunakan oleh pendidik Amerika David W. Orr dan fisikawan Fritjof Capra pada tahun 1990 untuk mengenalkan pola hidup ramah terhadap lingkungan sekitar melalui praktik pendidikan nilai. Nilai- nilai yang diberikan adalah nilai tanggung jawab dan cinta pada bumi. Proses ecoliteracy sesungguhnya adalah proses sepanjang hayat yaitu berawal dengan membentuk kesadaran pada suatu individu tentang pentingnya hidup bersinergi dengan alam semesta.

Hyun (2000) menjelaskan bahwa manusia mempunyai kesadaran akan ekologi namun kesadaran manusia tersebut harus dimunculkan melalui pengetahuan dan pemahaman tentang alam semesta tujuannya adalah agar kesadaran tersebut muncul menjadi suatu perilaku yang nampak nyata dalam menjaga bumi tempat dirinya hidup.

Ecoliteracy dapat menuntun manusia hidup selaras dengan alam terlihat dari adanya pola gaya hidup yang dimiliki seseorang dalam mencintai alam semesta sehingga gaya hidup tersebut dapat berkembang menjadi sebuah budaya cinta terhadap alam semesta yang akan mempengaruhi pola hidup masyarakat dunia. Puk \& Behm (2003) menjelaskan bahwa sadar akan lingkungan hidup merupakan cara berpikir seseorang hasil dari kesadaran manusia dalam menjaga ekologis yang dapat dilihat dari interaksi dirinya dengan alam sekitar yang akan mempengaruhi keseimbangan ekologi global.

Kesadaran lingkungan amatlah penting dalam mewujudkan tingkah laku perlindungan lingkungan. Seseorang akan melakukan perlindungan lingkungan apabila ia menyadari bahwa lingkungan yang berada disekitarnya perlu dilindungi. Seseorang akan muncul kesadaran lingkungannya, apabila ia memiliki sikap yang postif terhadap lingkungan.

Kesadaran lingkungan akan terkait pula dengan dukungan sosial. Artinya, apabila dukungan sosialnya kuat untuk melakukan perlindungan lingkungan, maka keadaran lingkunannya pun semakin kuat. Namun apabila dukungan sosialnya kurang kuat, kesadaran lingkungan belum dapat dipastikan akan kuat atau bahkan tidak memiliki kesadaran terhadap lingkungan.

Diperkuat oleh Lickona (2013) yang menjelaskan bahwa sesuatu karakter positif berawal dari adanya kesadaran (awareness), pemahaman (understanding), kepedulian (concern) dan komitmen (commitment) menuju tindakan (doing atau acting). Oleh karena itu, keberhasilan penanaman karakter cinta lingkungan sangat bergantung pada ada tidaknya kesadaran, pemahaman, kepedulian dan komitmen dari seseorang.

Maka dari itu ecoliteracy dapat diartikan sebagai kesadaran yang dimiliki oleh seseorang tentang pentingnya menjaga dan mengolah sumber alam. Seseorang yang telah memiliki pemahaman tentang ecoliteracy adalah individu yang memiliki kesadaran bahwa begitu pentingnya menjaga dan merawat bumi sebagai tempat tinggal dan berkembangnya kehidupan.

\section{METODE}

Pendekatan yang digunakan dalam studi ini yaitu menggunakan pendekatan kualitatif yang bersifat literature review dengan tekhnik systematic mapping study sebagai penelusuran pustakanya. Kegiatan literature review systematic mapping studybertujuan untuk menganalisis trend isu atau topik penelitian yang telah ditetapkan sebelumnya dan dianalisis sesuai dengan perkembangan keilmuan yang relevan. Langkah-langkah kegiatan literature review systematic mapping study yang dilakukan adalah sebagai berikut: 




Gambar 1. Tahapan Pelaksanaan Penelitian

1. Textbook, pada tahap ini dilakukan pengkajian mengenai isu yang berhubungan dengan dengan earth issue melalui buku-buku grand master yang untuk memperdalam pengetahuan mengenai bahan kajian.

2. Related research. Yaitu upaya mencari hasil penelitian yang berhubungan dengan isu yang akan diteliti dengan membaca jurnal-jurnal penelitian terbaru dan relevan baik jurnal bersekala Nasional maupun Internasional yang diakses secara manual fisik maupun dengan melakukan online aceses. Selain membaca jurnal-jurnal penelitian, analisis hasil penelitian terdahulu juga dapat diperoleh dari hasil- hasil pertemuan ilmiah dalam bentuk proseding yang berkaitan dengan green behaviour, ecoliteracy dan pendidikan anak usia dini.

3. State-of-the-art research, pada tahap ini dilakukan proses menganalisis teori-teori yang didapatkan dari sumber buku, hasil penelitian baik dari sumber jurnal maupun proseding untuk dijadikan sintesa.

\section{PEMBAHASAN}

Pengenalan nilai-nilai cinta lingkungan pada anak usia dini dapat diberikan melalui keteladanan, pembiasaan, dan pengulangan dalam kehidupan sehari-hari. Suasana dan lingkungan yang aman dan nyaman, perlu diciptakan dalam proses penanaman nilai-nilai cinta lingkungan. Pengenalan nilai cinta lingkungan pada anak bukan hanya sekadar mengharapkan kepatuhan, tetapi harus disadari dan diyakini oleh anak sehingga mereka merasa bahwa nilai tersebut memang benar dan bermanfaat untuk dirinya dan lingkungannya.

Sejalan dengan pemaparan dari Kemendikbud (2015) bahwa pengenalan nilai-nilai pada anak usia dini harus diberikan oleh orang dewasa dengan beberapa cara yaitu:

1. Menyadari bahwa nilai-nilai merupakan dasar segala tingkah laku dan menjadikan diri sebagai teladan utama bagi anak-anak.

2. Menentukan nilai-nilai yang paling sesuai serta menunjukkan nilai-nilai mana yang harus diutamakan melalui kegiatan dan pengalaman sehari-hari.

3. Menunjukkan pribadi yang ramah, positif, dan terintegrasi.

4. Menghadapi anak dengan penuh penghargaan, cinta, dan pengertian.

5. Meyakini akan nilai-nilai yang paling sesuai untuk dimiliki.

6. Menciptakan pengalaman yang bernilai dan bermakna bersama anak, kemudian menanyakannya kepada anak tentang bagaimana sebaiknya harus mengambil pilihan atau keputusan.

Orang dewasa dapat terlebih dahulu memberikan kesadaran lingkungan pada anak dengan cara menanamkan nilai-nilai cinta lingkungan melalui kegiatan yang membuat anak tertarik salah satunya dengan cara bercerita yang berhubungan dengan kegiatan menjaga lingkungan sekitar. Bercerita pada anak tentang pentingnya menjaga lingkungan hidup dapat dikatakan sebagai pengenalan ecoliteracy. Menurut Gunarti, Suryani, \& Muis (2008) tujuan yang ingin dicapai dalam kegiatan bercerita adalah mengembangkan kemampuan berbahasa, serta kemampuan menanamkan pesan-pesan moral yang terkandung dalam cerita tersebut.

Selain bercerita memberikan kesadaran lingkungan pada anak dapat dilakukan dengan mengajak anak melakukan kegiatan field-trip atau karyawisata. Kegiatan field-trip dapat dilakukan dengan mengunjungi perkebunan, perternakan, kebun binatang, taman, hutan lindung, bumi perkemahan atau tempat agrowisata lainnya. Kegitan field-trip dapat 
menciptakan suasana baru dan menyenangkan bagi anak dalam mempelajari alam sekitar karena anak dapat mengeksplor secara langsung lingkungan yang mereka kunjungi.

Juniarti (2015) dalam penelitiannya memaparkan bahwa metode pembelajaran fieldtrip dapat meningkatkan kecerdasan naturalis anak usia dini. Kegiatan field-trip dapat menghadirkan suasana belajar yang berbeda dari sebelumnya dimana anak-anak mampu mengenal langsung obejek yang akan dikunjunginya seperti melihat langsung aneka jenis flora dan fauna.

Desfandi, Maryani, \& Disman (2017) menjelaskan bahwa ecoliteracy menggambarkan kesadaran tentang pentingnya manusia menjaga lingkungan hidup. Ketika seseorang telah sangat menyadari betapa pentingnya lingkungan hidup serta pentingnya menjaga dan merawat bumi sebagai alam tempat tinggal makhluk hidup berati seseorang tersebut sudah masuk pada taraf ecoliteracy. Ketika seseorang telah mencapai taraf ecoliteracy dipastikan seseorang tersebut memiliki green behaviour. Pola seseorang yang memiliki green behaviour yaitu mempunyai perilaku menghormati bumi, merawat kehidupan dan mengadopsi pola produksi, konsumsi, dan reproduksi yang di sediakan oleh alam.

Hal ini sejalan dengan penelitian Dahlia (2014) yang dilakukan di PAUD Jogja Green School. Temuan yang dihasilkan dari penelitiannya mengungkapkan bahwa PAUD tersebut mengenalkan kesadaran ekologi kepada anak dengan menggunakan model pendidikan berbasis sistem belajar kembali ke alam di mana alam sekitar dijadikan sebagai laboratorium utama anak untuk mencari sumber pengetahuannya.

Diperkuat dengan penelitian yang dilakukan Jhonson (2014) tentang pengenalan ecoliteracy yang dilakukan kepada anak usia 2- 6 tahun di Amerika menemukan bahwa anakanak akan mempunyai kesdaran ekologi ketika mereka berada dalam satu kelompok bermainnya melakukan kegiatan di alam seperti menjelajah alam bersama dan bermain bersama di sungai sehingga pada akhirnya anak-anak akan menampakan perilaku green behaviour seperti bijak dalam menggunakan air, tidak membuang sampah sembarangan dan mau merawat tanaman.

Kegiatan proyek dimulai dari mengajarkan anak untuk menanam tanaman herbal, merawatnya, memanennya, membuat pupuk kompos sampai dengan mengkonsumsi hasil panennya sendiri. Sehingga selain memunculkan green behaviour pada anak melalui ecoliteracy perilaku positif lainnya pun dimunculkan, perilaku yang muncul tersebut adalah perilaku hidup sehat dan toleransi.

Penjelasan di atas sejalan dengan prinsip yang dimiliki oleh Center for Ecoliteracy (2015) yang menyatakan bahwa ecoliteracy akan menghasilkan green behaviour yang mana ketika sudah terdapat suatu kedinamisan diantara kedunya maka akan menghasilkan gaya hidup manusia di abad 21 yaitu manusia yang sehat, sejahtera dan mampu hidup menjaga mata rantai ekologi dengan seimbang.

\section{E. KESIMPULAN DAN SARAN}

Mengenalkan green behaviour melalui ecoliteracy pada anak usia dini dapat diberikan melalui keteladanan, pembiasaan, dan pengulangan dalam kehidupan sehari-hari oleh orang dewasa dengan cara yang menarik. Terdapat beberapa cara yang menarik untuk mengenalkan green behaviour melalui ecoliteracy pada anak usia dini yang didapat dari hasil pengkajian penelitian-penelitian relevan antara lain dengan cara menggunakan metode bercerita, melakukan kegiatan field-trip atau karyawisata, dan melakukan kegiatan proyek memelihara lingkungan sekitar. 


\section{DAFTAR PUSTAKA}

Capra. F, \& Stone, K, Michael. (2010). Smart by Nature: Schooling for Sustainability. The Journal of Sustanaibilty Education. [Online] June, 20, 2017. Retrived from: http://www.susted.com/wordpress/content/trial-author-change_2010_05/

Center for Ecoliteracy. (2015). Cultivating 20 Years of Ecoliteracy. California: Center for Ecoliteracy.

Dahlia (2014). Pendidikan anak usia dini berwawasan lingkungan dan budi pekerti di joga green school. Thesis. Yogyakarta: UIN Sunan Kalijaga.

Desfandi, Mirza,.Maryani, Enok,. \& Disman. (2017). Enhancing the role of early childhood education institution in an effort to grow ecoliteracy. Proceeding Advances in Social Science, Education and Humanities Research (ASSEHR). 58, p. 312.

Gunarti, Winda,. Suryani, Lilis,. \& Muis, Azizah. (2008). Metode pengembangan perilaku dan kemampuan dasar anak usia dini. Jakarta : Universitas Terbuka.

Goleman, D,. \& Barlow, Z (2012). Ecoliterate: how educators are cultivating emotional, social an ecological intelligence. Jossey Bass. A Wiley Imprint. USA Healdsburg, CA: Watershed Media.

Hyun, E. (2000). Ecological human brain and young children's 'naturalist intelligence' from the perspective of developmentally and culturally appropriate practice (DCAP). Presented at the Annual Conference of the American Educational Research Association. New Orleans, LA: American Educational Research Association.

Johnson, Kelly. (2014). Creative connecting: early childhood nature journaling sparks wonder and develops ecological literacy. International Journal of Early Childhood Environmental Education. 2 (1), p. 126.

Juniarti, Yenti. (2015). Peningkatan kecerdasan naturalis melalui metode kunjungan lapangan (field trip) (Penelitian tindakan di BPAUD terpadu Bintuhan Bengkulu Tahun 2015). Jurnal Pendidikan Anak Usia Dini. 9 (2), p. 267.

Kemendikbud. (2015). Penanaman sikap pendidikan anak usia dini. Jakarta: Direktorat Pembinaan Pendidikan Anak Usia Dini.

Lickona, Thomas. (2013). Mendidik untuk membentuk karakter: Bagaimana sekolah dapat memberikan pendidikan tentang sikap hormat dan tanggung jawab. Jakarta: Bumi Aksara.

Puk, T.G. \& Behm, D. (2003). The diluted curriculum: the role of government in developing ecological literacy as the first imperative in ontario secondary schools. Canadian Journal of Environmental Education. 8, p. 217-232.

Syaodih, Ernawulan, \& Handayani, Hany. (2015). Menumbuhkan green behaviour pada anak usia dini melalui pembelajaran proyek. Proceeding $6^{\text {th }}$ Pedagogy International Seminar 2015. II, p. 521. 